\title{
Cyst Type Differentiates Rathke Cleft Cysts From Cystic Pituitary Adenomas
}

\author{
Sherwin Tavakol ${ }^{1,2}$, Michael P. Catalino ${ }^{3}$, David J. Cote ${ }^{1,4}$, Xian Boles ${ }^{1}$, \\ Edward R. Laws Jr ${ }^{1 * t}$ and Wenya Linda $\mathrm{Bi}^{1 * t}$ \\ 1 Department of Neurosurgery, Brigham and Women's Hospital, Harvard Medical School, Boston, MA, United States, \\ 2 Department of Neurosurgery, University of Oklahoma Health Sciences Center, Oklahoma City, OK, United States, \\ ${ }^{3}$ Department of Neurosurgery, University of North Carolina Hospitals, Chapel Hill, NC, United States, ${ }^{4}$ Department of \\ Neurosurgery, Keck School of Medicine of USC, Los Angeles, CA, United States
}

OPEN ACCESS

Edited by:

Zhixiong Liu,

Central South University, China

Reviewed by: Min Guo,

Fudan University, China Xiaohai Liu, Capital Medical University, China Zhaohui He,

Chongqing Medical University, China

${ }^{*}$ Correspondence:

Edward R. Laws Jr elaws@bwh.harvard.edu

Wenya Linda Bi wbi@bwh.harvard.edu

${ }^{\dagger}$ These authors share senior authorship

Specialty section: This article was submitted to Neuro-Oncology and Neurosurgical Oncology, a section of the journal Frontiers in Oncology

Received: 17 September 2021 Accepted: 19 November 2021 Published: 10 December 2021

Citation:

Tavakol S, Catalino MP, Cote DJ, Boles X, Laws ER Jr and Bi WL (2021)

Cyst Type Differentiates Rathke Cleft Cysts From Cystic Pituitary Adenomas.

Front. Oncol. 11:778824. doi: 10.3389/fonc.2021.778824
Purpose: A classification system for cystic sellar lesions does not exist. We propose a novel classification scheme for these lesions based on the heterogeneity of the cyst wall/ contents and the presence of a solid component on imaging.

Methods: We retrospectively reviewed 205 patients' medical records (2008-2020) who underwent primary surgery for a cystic sellar lesion. Cysts were classified a priori into 1 of 4 cyst types based on the heterogeneity of the cyst wall/contents and the presence of a solid component imaging. There was high interrater reliability. Univariable and multivariable models were used to estimate the ability of cyst type to predict the two most common diagnoses: Rathke cleft cyst (RCC) and cystic pituitary adenoma.

Results: The frequencies of RCC and cystic pituitary adenoma in our cohort were $45.4 \%$ and $36.4 \%$, respectively. Non-neoplastic lesions (e.g., arachnoid cysts and RCC) were more likely to be Type 1 or 2, whereas cystic neoplasms (e.g., pituitary adenomas and craniopharyngiomas) were more likely to be Type 3 or $4(p<0.0001)$. Higher cyst types, compared to Type 1, had higher odds of being cystic pituitary adenomas compared to RCCs (OR: 23.7, $\mathrm{p}=0.033$, and 342.6, $\mathrm{p}<0.0001$, for Types 2 and 4, respectively). Lesions with a fluid-fluid level on preoperative MRI also had higher odds of being pituitary adenomas (OR: 12.7; $\mathrm{p}=0.023$ ). Cystic pituitary adenomas were more common in patients with obesity (OR: $5.0, p=0.003$ ) or symptomatic hyperprolactinemia (OR: 11.5; $p<0.001$, respectively). The multivariable model had a positive predictive value of $82.2 \%$ and negative predictive value of $86.4 \%$.

Conclusion: When applied to the diagnosis of RCC versus cystic pituitary adenoma, higher cystic lesion types (Type $2 \& 4$ ), presence of fluid-fluid level, symptomatic hyperprolactinemia, and obesity were predictors of cystic pituitary adenoma. Further validation is needed, but this classification scheme may prove to be a useful tool for the management of patients with common sellar pathology.

Keywords: cystic sellar lesion, pituitary adenoma, pituitary cyst, pituitary tumor, Rathke cleft cyst, craniopharyngioma 


\section{INTRODUCTION}

Cystic lesions in the sellar region encompass a broad gamut of pathologies, which can be challenging to distinguish on imaging, given their variability in clinical presentation and heterogeneity of cyst appearance. The presence of a sellar cyst generates a range of presumptive diagnoses - with pathologies including cystic pituitary adenomas, craniopharyngiomas, Rathke cleft cysts (RCC), arachnoid cysts, epidermoid cysts, dermoid cysts, and xanthogranulomas, among others $(1,2)$. Although some cystic lesions are benign, incidentally found lesions, others can lead to significant morbidity through disruption of hormonal axes or associated mass effect. Incidentally found lesions such as small pituitary adenoma or RCC may be observed, while surgical resection is indicated for symptomatic lesions or those requiring tissue diagnosis. Clinical and imaging factors are often used to generate a preliminary diagnosis and guide management. This variation in treatment pathways necessitates further study into the features that distinguish these various cystic pathologies, especially the two most common pathologies: RCC and cystic pituitary adenoma. No validated classification system of cystic sellar lesions exists. The localization of the lesion within the sella has been classically used to differentiate lesions originating from the pars intermedia (e.g., RCC) from those originating from the pars distalis (e.g., classic adenomas). Anterior lesions from the pars distalis often exhibit posterior displacement of the infundibulum, and posterior lesions from the pars intermedia often displace the infundibulum anteriorly. For large lesions extending into the suprasellar cisterns, the infundibulum is often hard to identify, and, therefore, this method cannot reliably predict the origin of the lesion. In this study, the classification scheme can be applied to every lesion, regardless of size using the heterogeneity of the cyst wall/ contents and presence of a solid component on preoperative magnetic resonance imaging (MRI). We used this a priori classification scheme and applied it to a retrospective cohort of patients.

\section{MATERIALS AND METHODS}

We retrospectively queried an institutional neurosurgical database from April 2008 to January 2020 for cases with the keywords "cyst" and "cystic" in preoperative radiology reports. Only patients with a final tissue diagnosis after surgical excision and/or cyst drainage were included in the study. Patients with non-sellar cysts, such as pineal cyst or epidermal inclusion cyst, were excluded. This study was approved by our institutional review board for ethical conduct of research and protection of human subjects. Patient consent was not required since no identifying information was used in this article.

Our primary aim was to apply an a priori cyst classification scheme and compare cystic lesion type with final pathologic diagnosis. Pre-operative thin-slice MRI (1.5T or 3T) and clinical and biochemical data were reviewed for each case. T1 pre- and post-gadolinium contrast images were reviewed along with T2- weighted images. The cyst classification scheme was developed based on focused discussions amongst the authors prior to its application to cyst classification in a retrospective fashion. Classification was independently performed by three authors (ST, MPC, and DJC) who were blinded from the final cyst pathology. Agreement by two or more authors was required for final cyst classification. Inter-rater reliability was assessed using Fleiss' kappa ( $\kappa)$. Confirmed lesion identity was extracted from pathology reports. Fisher's exact test was used to evaluate the relationship between cystic lesion type and lesion pathology.

The primary objective of the study was to estimate the association between cyst type and pathology, especially as it helped distinguish RCC from cystic pituitary adenomas. Cystic lesions were classified by the heterogeneity of the cyst wall/ contents and the presence of a solid component on preoperative MRI (Figure 1). Type 1 cystic lesions were defined by a wellcircumscribed regular border and homogeneous contents with no solid component (i.e. containing cyst contents and cyst wall only). Type 2 cystic lesions were defined by a well-circumscribed but irregular border with heterogenous content/septations and a subtle solid, non-cystic component. Type 3 lesions were defined by a well-circumscribed regular boarder and homogenous contents (like Type 1), but with an obvious solid component. Type 4 lesions were defined by irregular borders with heterogenous contents/septations (like Type 2) with multiple cysts, was predominately solid, and sometimes not wellcircumscribed (Figure 2). The radiographic classification scheme was consistent and easy to apply. There was unanimous consensus on cyst type for $91 \%$ of cases, and $100 \%$ agreement between at least 2 of the 3 reviewers $(\kappa=0.86)$.

\section{Data Analysis}

Student's t-test, Wilcoxon rank sum tests, Chi-square tests, and Fisher's exact tests were used for the comparison of continuous and categorical covariates of interest. A purposeful selection approach was used to create a multivariable logistic model. Odds ratios (OR), 95\% confidence intervals, and p-values are reported, in addition to receiver operating characteristics (ROC) analysis. All analyses were performed using the SAS/STAT software (Version 9.4, 2013; Cary, NC). Statistical significance was defined as $\mathrm{p}<0.05$.

\section{RESULTS}

We originally queried an institutional database of 1083 transsphenoidal operations in 982 patients for sellar pathology (757 operations for pituitary adenoma) performed by one of the senior authors (ERL) from April 2008 to January 2020. In total, 205 patients were found to have undergone transsphenoidal surgery for cystic sellar pathology. We classified the lesions of these patients (mean age 42 years, range 16-90 years; 68\% women) into the four cyst types (Table 1). Type 1 and 2 cysts were the most prevalent ( $33 \%$ and $35 \%$, respectively), with $5 \%$ of lesions being classified as Type 3 , and $27 \%$ as Type 4 . In our cohort, RCC and cystic pituitary adenomas comprised the vast 

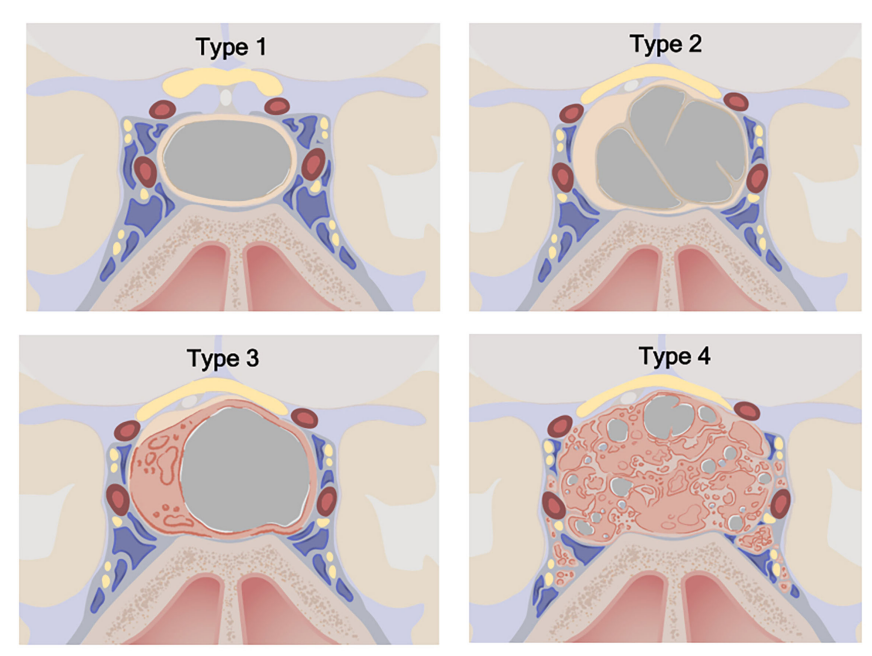

FIGURE 1 | Cystic sellar lesion classification scheme. Type 1: No solid component; well-circumscribed, homogenous cyst. Type 2: Little or no solid component; irregular cyst, with septations or abnormal walls. Type 3: Obvious solid component; well-circumscribed homogenous cyst. Type 4: Obvious solid component present; irregular cyst(s) with septations or abnormal walls. Type 1: $n=68$ (33.2\%), Type 2: $n=72$ (35.1\%), Type 3: $n=10$ (4.9\%), Type 4: $n=55$ (26.8\%). C2020 Xian Boles, Used by permission.

majority of cystic lesions ( $36 \%$ and $45 \%$, respectively). Arachnoid cysts $(7 \%)$ and craniopharyngiomas $(6 \%)$ were the next most common, with only one patient each having a pathologic diagnosis of chordoma, apoplexy without evident tumor, epidermoid cyst, and colloid cyst. There was a significant

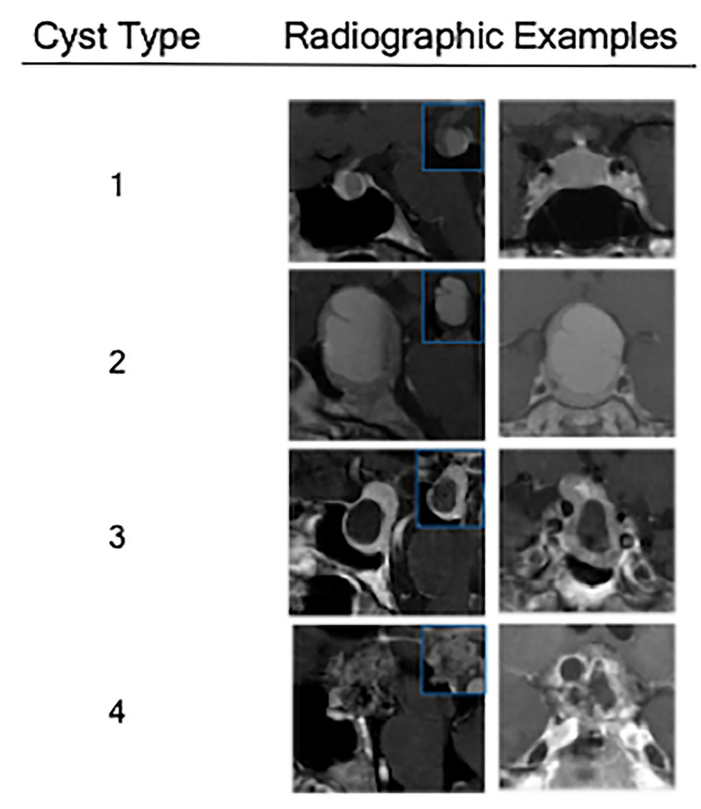

FIGURE 2 | Radiographic examples of each class of cystic sellar masses, with illustrative sagittal post-contrast T1-weighted MRI (left), sagittal precontrast T1-weighted MRI (small box), and coronal post-contrast T1-weighted $\mathrm{MRI}$ (right). association between cyst type and histopathologic diagnosis $(\mathrm{p}<0.0001$; Table 2).

The majority of the cystic pituitary adenomas were nonstaining tumors (38.7\% of adenomas), with prolactin- $(31.2 \%)$ and ACTH-staining (11.8\%) tumors following in prevalence. Approximately $46.2 \%$ of pituitary adenomas exhibited evidence of hormone secretion, and the remainder were non-functioning. Among the functioning tumors, $67.4 \%$ were prolactinomas, $18.6 \%$ presented with Cushing disease and $9.3 \%$ were associated with acromegaly. Roughly $30 \%$ of patients presented with symptomatic hypopituitarism, and roughly $25 \%$ of patients exhibited clinical signs of hyperprolactinemia (Table 1).

\section{Cyst Type and Pathology}

Cyst Type 1 lesions ( $n=68,33.2 \%$ of total) were largely comprised of RCCs $(n=44,65 \%)$, followed by cystic pituitary adenomas $(\mathrm{n}=14,21 \%)$ and arachnoid cysts $(\mathrm{n}=8,12 \%)$. They were nearly twice as likely to be located posteriorly, and were also, on average, smaller than other cystic lesion types - only $60 \%$ had a maximal diameter larger than $1 \mathrm{~cm}$. Type 1 lesions rarely showed radiographic evidence of cavernous sinus invasion (3\%). Additionally, clinical evidence of a headache was a common symptom seen in $78 \%$ of patients. Finally, patients with Type 1 lesions were younger and more likely to be female (mean age: 37 years; $84 \%$ female).

Cyst Type 2 lesions ( $n=72,35.1 \%$ of total) were primarily either an RCC $(n=29,43 \%)$ or a cystic pituitary adenoma $(n=28$, $41 \%)$. These lesions, unlike Type 1 lesions, were located anteriorly in $65 \%$ of cases. The higher proportion of cystic pituitary adenomas among this cyst type is in agreement with the anterior predominance. Furthermore, as expected, all adenomas in our cohort, regardless of cyst type, were more 
TABLE 1 | Preoperative patient/lesion characteristics, including patient demographic data, tumor symptoms, serum hormone levels, and radiographic features.

\begin{tabular}{|c|c|}
\hline & $\mathbf{N}(\%)$ \\
\hline Age, mean (range) & $41.7(16-90)$ \\
\hline \multicolumn{2}{|l|}{ Sex } \\
\hline Male & $66(32.2)$ \\
\hline Female & $139(67.8)$ \\
\hline \multicolumn{2}{|l|}{ Obesity } \\
\hline Yes & $70(34.1)$ \\
\hline No & $135(65.9)$ \\
\hline \multicolumn{2}{|l|}{ History of Other Cysts } \\
\hline Ovarian, n (\% of women) & $21(15.1)$ \\
\hline Renal & $10(4.9)$ \\
\hline Hepatic & $2(1.0)$ \\
\hline Adrenal & 0 \\
\hline Pineal Gland & $2(1.0)$ \\
\hline PCOS, n (\% of women) & $5(3.6)$ \\
\hline \multicolumn{2}{|l|}{ Inclusion } \\
\hline Cyst mentioned on radiology report & $166(81.4)$ \\
\hline Cyst not mentioned, but seen on T2 image & $38(18.6)$ \\
\hline \multicolumn{2}{|l|}{ Clinical Presentation } \\
\hline Headache & $132(64.4)$ \\
\hline Visual abnormalities & $71(34.8)$ \\
\hline Symptomatic hypopituitarism & $69(33.7)$ \\
\hline Symptomatic hyperprolactinemia & $51(25.0)$ \\
\hline Apoplexy & $4(1.9)$ \\
\hline \multicolumn{2}{|l|}{ Hormonal abnormalities } \\
\hline Hyperprolactinemia & $97(47.3)$ \\
\hline GH deficient & $13(6.3)$ \\
\hline Acromegaly & $4(2.0)$ \\
\hline Cortisol deficient & $28(13.7)$ \\
\hline Cushing disease & $8(3.9)$ \\
\hline Gonadotropin deficient & $42(20.5)$ \\
\hline Thyroid deficient & $39(19.0)$ \\
\hline Thyroid excess & $2(1.0)$ \\
\hline Pre-operative ADH deficient & $10(4.9)$ \\
\hline \multicolumn{2}{|l|}{ Cyst Category } \\
\hline Type 1 & $68(33.2)$ \\
\hline Type 2 & $72(35.1)$ \\
\hline Type 3 & $10(4.9)$ \\
\hline Type 4 & $55(26.8)$ \\
\hline \multicolumn{2}{|l|}{ Lesion Location } \\
\hline Anterior & 125 (61.0) \\
\hline Posterior & $80(39.0)$ \\
\hline \multicolumn{2}{|l|}{ Maximum diameter (cm) } \\
\hline$\geq 10 \mathrm{~mm}$ & $151(73.7)$ \\
\hline$<10 \mathrm{~mm}$ & $54(26.3)$ \\
\hline \multicolumn{2}{|l|}{ Knosp Score } \\
\hline $0-2$ & $183(88.8)$ \\
\hline $3-4$ & $23(11.2)$ \\
\hline Fluid-Fluid level & 27 (13.2) \\
\hline
\end{tabular}

likely than RCCs to be anteriorly located $(\mathrm{p}=0.029)$. Finally, although $72 \%$ of Type 2 cysts were larger than $1 \mathrm{~cm}$ in diameter, these cysts rarely exhibited cavernous sinus invasion (1\%).

Cyst Type 3 lesions ( $n=10,4.9 \%$ of total) represented the least prevalent cyst type, and only consisted of RCCs $(n=3,30 \%)$ and cystic pituitary adenomas $(n=7,70 \%)$. Six of the seven $(86 \%)$ cystic pituitary adenomas were located anteriorly, and all RCCs were posterior lesions. All Type 3 cysts had a maximal diameter greater than $1 \mathrm{~cm}$, with a mean maximal diameter of $1.9 \mathrm{~cm}$.

Cyst Type 4 lesions ( $n=55,26.8 \%$ of total) were mostly cystic pituitary adenomas $(n=45,83 \%)$. Only $15 \%$ of Type 4 cystic lesions were craniopharyngiomas, although, the majority of craniopharyngiomas (62\%) fell into this category. These lesions were located anteriorly $82 \%$ of the time, and Type 4 lesions were, on average, larger than other cyst types; $87 \%$ of Type 4 lesions were larger than $1 \mathrm{~cm}$ in diameter. Type 4 lesions were the most likely to show evidence of cavernous sinus invasion on preoperative MRI (35\%). They were also most likely to have evidence of pre-operative visual abnormalities (62\%). Finally, patients with these complex cysts were, on average, older than other patients, with a mean age of 50 years.

\section{Differentiating Rathke Cleft Cysts and Cystic Pituitary Adenoma}

Type 2 and 4 lesions were significantly more likely to be diagnosed as cystic pituitary adenomas compared to Type 1 lesions (OR: 23.7, 342.6; $\mathrm{p}=0.033, \mathrm{p}<0.0001$, respectively; Table 3). Those with Type 3 lesions had over a 5 -fold increase in odds of being diagnosed as cystic pituitary adenomas as compared with RCC but this did not reach statistical significance, likely due to low power. A fluid-fluid level on preoperative MRI was significantly associated with a cystic pituitary adenoma (OR: 12.7; $\mathrm{p}=0.023$ ). Obesity (OR: 5.0, $\mathrm{p}=0.003$ ) and symptomatic hyperprolactinemia (OR: 11.5, $\mathrm{p}<0.001)$ were also significantly associated with cystic pituitary adenomas. Interestingly, although lesion relationship to the infundibulum (anterior versus posterior) was significant on univariable analysis, this was not statistically significant in the multivariable model. Additionally, we investigated whether the presence of Cushing disease or elevated serum cortisol level was driving the association between obesity and presence of a pituitary adenoma, however, these confounders were not found to be significant, and obesity was thus shown to be a true independent predictor of adenoma. Similarly, confounding of

TABLE 2 | Cyst category by pathologic diagnosis.

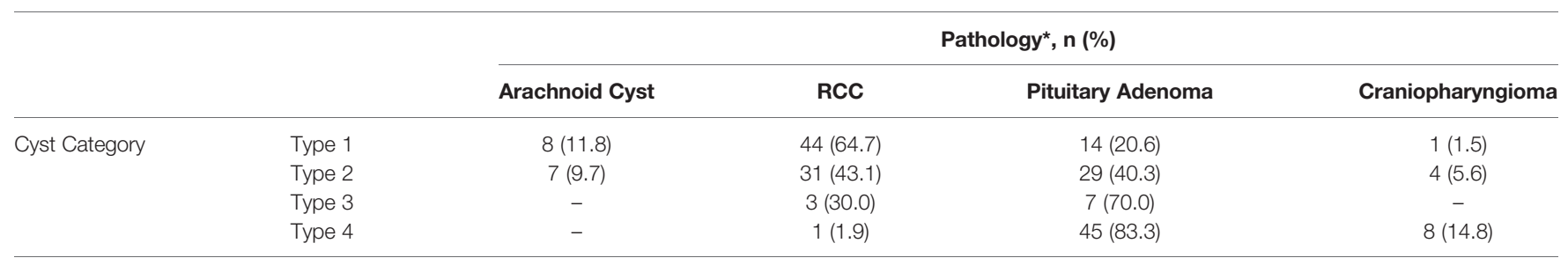

${ }^{*} p<0.001$.

The distribution of the four main pathologies represented by each of the cyst types in our cohort is presented. One colloid cyst (Type 1), one epidermoid cyst (Type 2), and one chordoma (Type 4) are not represented in this table. 
TABLE 3 | Adjusted predictors of cystic pituitary adenomas versus Rathke cleft cysts.

\begin{tabular}{lccc}
\hline & Odds Ratio & $\begin{array}{c}\mathbf{9 5 \%} \text { Confidence } \\
\text { Interval }\end{array}$ & P-value \\
\hline Cyst Type 1 & REF & REF & REF \\
Cyst Type 2 & 23.7 & $1.3-10.6$ & $\mathbf{0 . 0 3 3}$ \\
Cyst Type 3 & 5.3 & $0.9-31.9$ & 0.430 \\
Cyst Type 4 & 342.6 & $36.2-999.9$ & $<\mathbf{0 . 0 0 0 1}$ \\
Fluid-Fluid Level & 12.7 & $1.4-111.9$ & $\mathbf{0 . 0 2 3}$ \\
Symptomatic Hyperprolactinemia & 11.5 & $3.6-37.1$ & $<\mathbf{0 . 0 0 0 1}$ \\
Obese & 5.0 & $1.8-14.2$ & $\mathbf{0 . 0 0 3}$ \\
\hline
\end{tabular}

Odds ratios (OR), 95\% confidence intervals (Cl), and $p$-values for predictors of cystic pituitary adenoma compared to Rathke cleft cyst (RCC) in our cohort are presented. Bolded P-values indicate statistical significance.

symptomatic hyperprolactinemia by lesion size was also assessed, but not determined to be significant, and thus, only symptomatic hyperprolactinemia was included in the final model. Our multivariable clinical and radiographic model correctly predicted pathology $83.8 \%$ of the time (AUC 0.922 ; sensitivity $90.2 \%$, specificity $76.0 \%$, positive predictive value $82.2 \%$, negative predictive value $86.4 \%$; Table 3 ).

\section{DISCUSSION}

Differentiating cystic sellar lesions can be challenging given the heterogeneity of cyst appearance on preoperative imaging and the wide array of cystic pathologies that can present in this region. The initial differential strongly impacts the recommended management, especially in incidentally found lesions. Our proposed classification system is transparent and simple to use with a high interrater reliability. It summarizes key imaging features and may be most helpful when used alongside clinical and biochemical findings to steer management and treatment.

\section{Differentiating Cystic Sellar Lesions}

Key differentiating features among cystic lesions include heterogeneity of cyst contents, thickness of the cyst wall, cyst location (anterior versus posterior and midline versus lateral location), globular versus eccentric shape, size, degree of invasiveness, presence of solid component, and presence of intracystic nodule (3-19). We distilled these radiographic characteristics to two main factors: heterogeneity of cyst wall/ contents and the presence of solid component. Overall, cyst type was found to be significantly associated with lesion pathology $(\mathrm{p}<0.0001)$, with non-neoplastic pathologies (e.g., arachnoid cysts and RCC) falling within Types 1 and 2, and neoplastic lesions (e.g., pituitary adenomas and craniopharyngiomas) categorized more frequently as Types 3 and 4. Interestingly, although the vast majority of Type 2 lesions were larger than $1 \mathrm{~cm}(72 \%)$, these cysts rarely exhibited cavernous sinus invasion (1\%). This finding suggest that Type 2 cysts are associated with less invasive pituitary adenomas, which represented $41 \%(n=28)$ of type 2 cystic lesions.

\section{Predictors of Cystic Pituitary Adenoma}

This classification scheme has predictive value in a multivariable model differentiating between RCC and cystic pituitary adenoma in the pre-operative setting, correctly predicting the pathology $83.8 \%$ of the time. Radiographic features (e.g., cyst Type $2-4$ and the presence of fluid-fluid level on MRI) and clinical/biochemical features (e.g., obesity and symptomatic hyperprolactinemia) were significant predictors of cystic adenomas. Our goal was to create a simple and effective tool for the clinician. Further in-depth analysis of multiple MRI and computed tomography sequences should also be employed to further aid in the differentiation of rare, but often misdiagnosed, cystic lesions, like hemorrhagic cystic pituitary adenomas (Table 4). Analogous to other reports, we observed that the presence of a fluid-fluid level on preoperative MRI is also predictive of cystic pituitary adenoma as compared with RCC (21, 28). We posit that the prevalence of fluid-fluid level among adenomas may be the result of intracystic hemorrhage from the abnormal vasculature architecture of these cystic lesions. We also redemonstrated that obesity is an independent predictor of pituitary adenoma $(29,30)$. Body mass index and waist circumference throughout early adulthood have been recently associated with higher risk of pituitary adenoma (31).

\section{Surgical Implications for Cystic Prolactinomas}

Indications for surgical resection of a pituitary mass include large lesions with mass effect and biochemically active tumors causing clinical hyperpituitarism $(2,32)$. Symptomatic hyperprolactinemia is the most common form of clinical hyperpituitarism and can be caused by a functional lactotroph tumor (prolactinoma) or stalk effect. Large cysts can produce stalk effect through compression of the infundibulum and suppression of dopaminergic negative feedback to the anterior pituitary gland. Prolactinomas directly secrete prolactin, which can be measured in the serum and used

TABLE 4 | Key preoperative radiographic findings for various cystic sellar pathology.

Rathke cleft cyst $(6,12,14,15,20)$

Hemorrhagic cystic pituitary adenoma (20-24)

Arachnoid cyst (6)

Dermoid cyst $(16,17)$

Epidermoid cyst $(16,19,25)$

Craniopharyngiomas $(24,26,27)$

\footnotetext{
- T2-hyperintense- Homogenously T2-hypointense/T1-hyperintense with high intrinsic protein content

- T2-hypointense/T1-hyperintense (can mimic RCC when solid component is lacking)

- Parallels CSF signal intensity on all MRI sequences

- Follows fat signal intensity on all MRI sequences

- Follows CSF intensity on T1 and T2, but bright on diffusion-weighted images (DWI)

- Contrast enhancement of solid portions on MRI- Intensity of cystic component can be variable depending on proportion of protein, cholesterol, and blood- 90\% exhibit calcification on CT
} 
in conjunction with tumor volume to diagnose a prolactinoma with high predictive value $(33,34)$. Cystic prolactinomas with minimal cellular/solid component, however, may not exhibit marked hyperprolactinemia, thereby mimicking hyperprolactinemia caused by stalk effect. This can lead to misclassification by conventional methods due to the mismatch between size and prolactin level, and, therefore, mimicking stalk effect. In our cohort, we found that the presence of clinical symptoms of hyperprolactinemia was one of the most predictive factors in diagnosing a cystic pituitary adenoma compared to an RCC, independent of serum prolactin level and lesion size. This important finding implies that careful distinction should be made between Type 1 and Type 2 lesions in the presence of a mild elevation of prolactin that may otherwise be attributable to stalk effect.

\section{CONCLUSION}

This study presents a novel cyst classification scheme for categorizing cystic sellar lesions based on the heterogeneity of the

\section{REFERENCES}

1. Cavallo LM, Prevedello D, Esposito F, Laws ER, Dusick JR, Messina A, et al. The Role of the Endoscope in the Transsphenoidal Management of Cystic Lesions of the Sellar Region. Neurosurg Rev (2008) 31(1):55-64. doi: 10.1007/ s10143-007-0098-0

2. Laws ER. Endoscopic Surgery for Cystic Lesions of the Pituitary Region. Nat Clin Pract Endocrinol Metab (2008) 4(12):662-3. doi: 10.1038/ ncpendmet0975

3. Park M, Lee SK, Choi J, Kim S-H, Kim SH, Shin N-Y, et al. Differentiation Between Cystic Pituitary Adenomas and Rathke Cleft Cysts: A Diagnostic Model Using MRI. AJNR Am J Neuroradiol (2015) 36(10):1866-73. doi: 10.3174/ajnr.A4387

4. Poussaint TY, Barnes PD, Anthony DC, Spack N, Scott RM, Tarbell NJ. Hemorrhagic Pituitary Adenomas of Adolescence. AJNR Am J Neuroradiol (1996) 17(10):1907-12.

5. Chabot JD, Chakraborty S, Imbarrato G, Dehdashti AR. Evaluation of Outcomes After Endoscopic Endonasal Surgery for Large and Giant Pituitary Macroadenoma: A Retrospective Review of 39 Consecutive Patients. World Neurosurg (2015) 84(4):978-88. doi: 10.1016/j.wneu. 2015.06.007

6. Zamora C, Castillo M. Sellar and Parasellar Imaging. Neurosurg (2017) 80 (1):17-38. doi: 10.1093/neuros/nyw013

7. Bonneville JF, Bonneville F, Cattin F. Magnetic Resonance Imaging of Pituitary Adenomas. Eur Radiol (2005) 15(3):543-8. doi: 10.1007/s00330004-2531-x

8. Shatri J, Ahmetgjekaj I. Rathke's Cleft Cyst or Pituitary Apoplexy: A Case Report and Literature Review. Open Access Maced J Med Sci (2018) 6(3):5447. doi: 10.3889/oamjms.2018.115

9. Gittleman H, Ostrom QT, Farah PD, Ondracek A, Chen Y, Wolinsky Y, et al. Descriptive Epidemiology of Pituitary Tumors in the United States, 20042009. J Neurosurg (2014) 121(3):527-35. doi: 10.3171/2014.5.JNS131819

10. Graziani N, Dufour H, Figarella-Branger D, Donnet A, Bouillot P, Grisoli F. Do the Suprasellar Neurenteric Cyst, the Rathke Cleft Cyst and the Colloid Cyst Constitute a Same Entity? Acta Neurochir (Wien) (1995) 133(3-4):17480. doi: 10.1007/BF01420070

11. Hama S, Arita K, Nishisaka T, Fukuhara T, Tominaga A, Sugiyama K, et al. Changes in the Epithelium of Rathke Cleft Cyst Associated With Inflammation. J Neurosurg (2002) 96(2):209-16. doi: 10.3171/jns.2002.96.2.0209

12. Kunii N, Abe T, Kawamo M, et al. Rathke's Cleft Cysts: Differentiation From Other Cystic Lesions in the Pituitary Fossa by Use of Single-Shot Fast Spin- cyst wall/contents and the presence of a solid component on preoperative MRI. We suggest that cyst type can be used in conjunction with other pre-operative factors to aid in the differentiating RCC from cystic pituitary adenomas, including cystic prolactinomas.

\section{DATA AVAILABILITY STATEMENT}

The raw data supporting the conclusions of this article will be made available by the authors, without undue reservation.

\section{AUTHOR CONTRIBUTIONS}

ST, MC, and DC were involved in data collection, data analysis, and manuscript writing. $\mathrm{XB}$ created figures and provided image formatting. EL provided the idea for the study and the cohort of cases from which the data was derived. All authors were heavily involved in manuscript editing. All authors contributed to the article and approved the submitted version.

Echo Diffusion-Weighted MR Imaging. Acta Neurochir (Wien) (2007) 149 (8):759-69. doi: 10.1007/s00701-007-1234-x

13. Laws ER, Kanter AS. Rathke Cleft Cysts. J Neurosurg (2004) 101(4):571-2. doi: 10.3171/jns.2004.101.4.0571

14. Nishioka H, Haraoka J, Izawa H, Ikeda Y. Magnetic Resonance Imaging, Clinical Manifestations, and Management of Rathke's Cleft Cyst. Clin Endocrinol (Oxf) (2006) 64(2):184-8. doi: 10.1111/j.1365-2265.2006.02446.x

15. Binning MJ, Gottfried ON, Osborn AG, Couldwell WT. Rathke Cleft Cyst Intracystic Nodule: A Characteristic Magnetic Resonance Imaging Finding. J Neurosurg (2005) 103(5):837-40. doi: 10.3171/jns.2005.103.5.0837

16. Caldarelli M, Massimi L, Kondageski C, Di Rocco C. Intracranial Midline Dermoid and Epidermoid Cysts in Children. J Neurosurg (2004) 100(5):47380. doi: 10.3171/ped.2004.100.5.0473

17. Orakcioglu B, Halatsch ME, Fortunati M, Unterberg A, Yonekawa Y. Intracranial Dermoid Cysts: Variations of Radiological and Clinical Features. Acta Neurochir (Wien) (2008) 150(12):1227-34. doi: 10.1007/ s00701-008-0152-x

18. Tatagiba M, Iaconetta G, Samii M. Epidermoid Cyst of the Cavernous Sinus: Clinical Features, Pathogenesis and Treatment. Br J Neurosurg (2000) 14 (6):571-5. doi: 10.1080/02688690050206747

19. Tsuruda JS, Chew WM, Moseley ME, Norman D. Diffusion-Weighted MR Imaging of the Brain: Value of Differentiating Between Extraaxial Cysts and Epidermoid Tumors. AJR Am J Roentgenol (1990) 155(5):1059-65. doi: 10.2214/ajr.155.5.2120936

20. Choi SH, Kwon BJ, Na DG, Kim JK, Han MH, Chang KH. Pituitary Adenoma, Craniopharyngioma, and Rathke Cleft Cyst Involving Both Intrasellar and Suprasellar Regions: Differentiation Using MRI. Clin Radiol (2007) 62(5):45362. doi: 10.1016/j.crad.2006.12.001

21. Xiao D, Wang S, Zhao L, Zhong Q, Huang Y, Ding C. Fluid-Fluid Level on Magnetic Resonance Images may Predict the Occurrence of Pituitary Adenomas in Cystic Sellar-Suprasellar Masses. Exp Ther Med (2017) 13 (6):3123-9. doi: 10.3892/etm.2017.4299

22. Mohr G, Hardy J. Hemorrhage, Necrosis, and Apoplexy in Pituitary Adenomas. Surg Neurol (1982) 18(3):181-9. doi: 10.1016/0090-3019(82) 90388-3

23. Tosaka M, Sato N, Hirato J, Fujimaki H, Yamiguchi R, Kohga H, et al. Assessment of Hemorrhage in Pituitary Macroadenoma by $\mathrm{T} 2 *$-Weighted Gradient-Echo MR Imaging. AJNR Am J Neuroradiol (2007) 28:2023-29. doi: 10.3174/ajnr.A0692

24. Shin JL, Asa SL, Woodhouse LJ, Smyth HS, Ezzat S. Cystic Lesions of the Pituitary: Clinicopathological Features Distinguishing Craniopharyngioma, 
Rathke's Cleft Cyst, and Arachnoid Cyst. J Clin Endocrinol Metab (1999) 84 (11):3972-82. doi: 10.1210/jcem.84.11.6114

25. Harrison MJ, Morgello S, Post KD. Epithelial Cystic Lesions of the Sellar and Parasellar Region: A Continuum of Ectodermal Derivatives? J Neurosurg (1994) 80(6):1018-25. doi: 10.3171/jns.1994.80.6.1018

26. Bunin GR, Surawicz TS, Witman PA, Preston-Martin S, Davis F, Bruner JM. The Descriptive Epidemiology of Craniopharyngioma. J Neurosurg (1998) 89 (4):547-51. doi: 10.3171/jns.1998.89.4.0547

27. Prabhu VC, Brown HG. The Pathogenesis of Craniopharyngiomas. Childs Nerv Syst (2005) 21(8-9):622-7. doi: 10.1007/s00381-005-1190-9

28. Goel A, Shah A, Jhawar SS, Goel NK. Fluid-Fluid Level in Pituitary Tumors: Analysis of Management of 106 Cases. J Neurosurg (2010) 112(6):1341-6. doi: 10.3171/2009.11.JNS091083

29. Hayashi M, Tachibana O, Muramatsu N, Tsuchiya H, Tada M, Arakawa Y, et al. Rathke Cleft Cyst: MR and Biomedical Analysis of Cyst Content. J Comput Assist Tomogr (1999) 23(1):34-8. doi: 10.1097/00004728199901000-00008

30. Zada G. Rathke Cleft Cysts: A Review of Clinical and Surgical Management. Neurosurg Focus (2011) 31(1):E1. doi: 10.3171/2011.5.FOCUS1183

31. Cote DJ, Smith TR, Kaiser UB, Laws ER, Stampfer MJ. Body Habitus Across the Lifespan and Risk of Pituitary Adenoma. J Clin Endocrinol Metab (2021) 106(4):e1591-602. doi: 10.1210/clinem/dgaa987

32. Zada G, Lin N, Ojerholm E, Ramkissoon S, Laws ER. Craniopharyngioma and Other Cystic Epithelial Lesions of the Sellar Region: A Review of Clinical, Imaging, and Histopathological Relationships. Neurosurg Focus (2010) 28 (4):4-5. doi: 10.3171/2010.2.FOCUS09318
33. Burke WT, Penn DL, Castlen JP, Donoho DA, Repetti CS, Luliano S, et al. Prolactinomas and Nonfunctioning Adenomas: Preoperative Diagnosis of Tumor Type Using Serum Prolactin and Tumor Size. J Neurosurg (2019) 133:321-8. doi: 10.3171/2019.3.JNS19121

34. Hamilton DK, Vance ML, Boulos PT, Laws ER. Surgical Outcomes in Hyporesponsive Prolactinomas: Analysis of Patients With Resistance or Intolerance to Dopamine Agonists. Pituitary (2005) 8(1):53-60. doi: $10.1007 / \mathrm{s} 11102-005-5086-1$

Conflict of Interest: The authors declare that the research was conducted in the absence of any commercial or financial relationships that could be construed as a potential conflict of interest.

Publisher's Note: All claims expressed in this article are solely those of the authors and do not necessarily represent those of their affiliated organizations, or those of the publisher, the editors and the reviewers. Any product that may be evaluated in this article, or claim that may be made by its manufacturer, is not guaranteed or endorsed by the publisher.

Copyright (c) 2021 Tavakol, Catalino, Cote, Boles, Laws and Bi. This is an open-access article distributed under the terms of the Creative Commons Attribution License (CC BY). The use, distribution or reproduction in other forums is permitted, provided the original author(s) and the copyright owner(s) are credited and that the original publication in this journal is cited, in accordance with accepted academic practice. No use, distribution or reproduction is permitted which does not comply with these terms. 